\title{
Comparing Stability Indices for Ripening Date and Yield in Blueberry
}

\author{
Creighton Gupton ${ }^{1}$ \\ U.S. Department of Agriculture-Agricultural Research Service, Small Fruit Research Station, Poplarville, \\ MS 39470
}

John Clark ${ }^{2}$

University of Arkansas, Fayetteville, AR 72701

David Creech ${ }^{3}$

Department of Agriculture, Stephen F. Austin State University, Nacogdoches, TX 75962

Arlie Powell ${ }^{4}$

Auburn University, Auburn, AL 36849

Susan Rooks ${ }^{5}$

Horticulture Crops Research Station, Castle Hayne, NC 28429

Additional index words. Vaccinium ashei, V. corymbosum, cluster analysis, blueberry breeding, regional germplasm evaluation, genotype-environment interactions, southern highbush blueberry

\begin{abstract}
To determine if any of the available techniques for estimating stability in different environments are useful in blueberry (Vaccinium ashei Reade and V. corymbosum $\mathrm{L}$.), 14 clones were evaluated in nine environments for ripening date and yield. Type 1 and 2 stability statistics, plots for each genotype mean versus its coefficient of variation (cv) across environments (genotype grouping), environmental index regression, and cluster analyses were compared. The highest yielding rabbiteye and southern highbush clones across locations were not deemed stable by Type 1 and Type 2 stability statistics, genotype grouping, or environmental regression technique. No evidence of curvilinear response was found. The nonparametric cluster analysis with known cultivars included appears to be most useful compared to other methods of estimating stability used in this study.
\end{abstract}

A southern regional blueberry germplasm evaluation program has been conducted since 1984 (Gupton et al., 1990). One of the objectives is to determine cultivar potential of selections across the southern United States. It would be useful also to have a measure of cultivar stability in different environments. A regression method for examining genotype $\times$ environment interactions was first proposed by Yates and Cockran (1938). Since that time several stability indices have been developed to assess adaptability of genotypes to environments. Lin et al. (1986) compared nine stability statistics proposed in eight publications and ten nonparametric clustering procedures from ten publications. They concluded that Type 1 stability (small among-environment variance) is often associated with poor response and low yield, and Type 2 stability (response of a genotype is parallel to the mean of all genotypes) is a relative measure depending on the genotypes included in the test. These authors contend that Type 3 stability (deviation from regression) is not appropriate unless the environmental index can be replaced with actual environmental factors. A small $R^{2}$ and large deviation mean square indicate a poor fit of the regression model and other approaches should be investigated to estimate stability. Lin et al. (1986) also stated that clustering allows subsets of genotypes to be described by the characteristics of the

Received for publication 18 Aug. 1995. Accepted for publication 21 Nov. 1995. The cost of publishing this paper was defrayed in part by the payment of page charges. Under postal regulations, this paper therefore must be hereby marked advertisement solely to indicate this fact.

${ }^{1}$ Research geneticist.

${ }^{2}$ Associate professor.

${ }^{3}$ Professor of agriculture.

${ }^{4}$ Extension horticulturist and professor.

${ }^{5}$ Research associate. separate groups, although not directly in terms of stability. If wellknown cultivars are included in the test, they may serve as paradigms for genotypes in the same cluster. Stability measures in nonparametric methods of evaluation are distribution-free and not affected by outliers (Nassar and Huhn, 1987).

Verma et al. (1978) proposed computing regression analyses for poor environments and good environments because, theoretically, the ideal genotype would be high yielding and stable in poor environments but respond to favorable environments. Francis and Kannenberg (1978) proposed plotting yield against coefficient of variation (cv) and dividing the plots into four groups with above and below average yield and above and below average cv.

Pritts and Luby (1990) reviewed stability indices for horticultural crops. They also compared coefficients of variation, square root of the variance estimates, regression coefficients on an environmental index, a two-regression model, and coefficients of determination in strawberry. Stability indices were not consistent in their evaluation of cultivar performance and some provided completely different assessments of genotypic stability. The authors concluded that drawing conclusions about the genetic basis of yield stability from cvs is difficult, and stability indices based on a regression approach have poor repeatability and many assumptions underlying the analysis are unlikely to be met.

Siefker and Hancock (1986), using regression of plot means for each genotype on yearly means and deviation from regression, found that high yielding highbush cultivars were more stable than lower yielding ones for 17 genotypes evaluated over 13 years at a single location. The objective of this study was to determine if any of the available techniques for estimating stability in different environments are useful in blueberry germplasm evaluations in the southern United States. 
Table 1 . Average rank of Type 1 and Type 2 stability statistics for ripening date and yield of seven rabbiteye and seven southern highbush clones grown in nine environments.

\begin{tabular}{|c|c|c|c|c|}
\hline \multirow[b]{2}{*}{ Clone } & \multicolumn{2}{|c|}{ Type 1} & \multicolumn{2}{|c|}{ Type 2} \\
\hline & $\begin{array}{c}50 \% \text { Ripe } \\
\text { (Julian date) }\end{array}$ & $\begin{array}{c}\text { Yield } \\
\text { (kg/plant) }\end{array}$ & $\begin{array}{c}50 \% \text { Ripe } \\
\text { (Julian date) }\end{array}$ & $\begin{array}{c}\text { Yield } \\
\text { (kg/plant) }\end{array}$ \\
\hline \multicolumn{5}{|l|}{ Rabbiteye } \\
\hline Bonita & $1.0^{\mathrm{z}}$ & 1.0 & 1.8 & 4.3 \\
\hline FL80-11 & 2.5 & 4.0 & 3.5 & 2.5 \\
\hline Tifblue & 2.5 & 6.5 & 5.5 & 5.0 \\
\hline T397 & 4.0 & 4.0 & 5.0 & 3.5 \\
\hline T340 & 5.5 & 4.5 & 2.8 & 5.0 \\
\hline T342 & 5.5 & 4.0 & 3.3 & 2.3 \\
\hline Climax & 7.0 & 4.0 & 6.3 & 5.0 \\
\hline \multicolumn{5}{|c|}{ Southern highbush } \\
\hline TH277 & 2.0 & 6.0 & 5.5 & 4.0 \\
\hline Gulfcoast & 2.5 & 6.5 & 2.5 & 4.5 \\
\hline MS107 & 2.5 & 2.0 & 3.5 & 2.5 \\
\hline MS109 & 3.0 & 3.0 & 5.0 & 3.0 \\
\hline MS115 & 5.3 & 2.5 & 4.0 & 5.5 \\
\hline MS108 & 5.8 & 3.5 & 3.0 & 5.0 \\
\hline Cooper & 7.0 & 4.5 & 4.5 & 3.5 \\
\hline
\end{tabular}

${ }^{\mathrm{z} L o w}$ values indicate most and high values least stable clones.

\section{Materials and Methods}

Estimates of ripening date and yield per plant were recorded in 1991 and 1992 from seven rabbiteye (RE) and seven southern highbush (SHB) blueberry clones (Table 1) in the Southern Regional Blueberry Germplasm Evaluation Trials planted in 1988. Data were recorded for 2 years at Clarksville, Ark.; Nacogdoches, Tex.; Poplarville, Miss.; and Castle Hayne, N.C., and for 1 year at Camp Hill, Ala., for a total of nine environments. Four replications were recorded using one plant from a two-plant plot. The rabbiteye and southern highbush clones were established in separate trials. Ripening date was estimated as the Julian date when $50 \%$ of the fruit was ripe, and yield consisted of the total fruit weight per plant.

Type 1 and Type 2 stability statistics. Stability statistics were computed according to Group A and B of Table 1 in Lin et al. (1986). The two Group A statistics are equivalent except for data preparation and were combined to produce Type 1 estimates wherein a genotype is considered to be stable if its among environment variance is small. For ranking purposes, the four statistics in Group B are equivalent and were combined to produce Type 2 estimates. Type 2 statistics indicate that a genotype is stable if its response to environments is parallel to the mean response of all genotypes in the trial.

Francis and Kannenberg grouping. Plots of each genotype mean across environments versus its $\mathrm{CV}$ across environments were constructed according to Francis and Kannenberg (1978). The y axis represents the mean response over nine environments and the $\mathrm{x}$ axis represents the $\mathrm{CV}$ of each genotype calculated across the environments. Vertical and horizontal reference lines were drawn on each plot to divide it into four quadrants; the vertical line was located at $\mathrm{x}=$ average of the seven cvs and the horizontal at $\mathrm{y}=$ average of the seven mean values. Points falling into one of the four quadrants, labelled as Group I, II, III, and IV, were interpreted as having above or below average mean response and above or below average $\mathrm{CV}$.

Environmental index regression. The modification of conventional regression analysis proposed by Verma et al. (1978) was performed for the purpose of identifying stable genotypes. The ripening date and yield values were regressed on an environmental index defined as the difference between the environment mean and the mean of the genotype across all environments. Poor environments were defined as those in which the associated genotype had an environmental index less than zero and good environments

Fig. 1. Clone ripening date means versus clone $\mathrm{CV}$ from seven rabbiteye clones grown in nine environments.

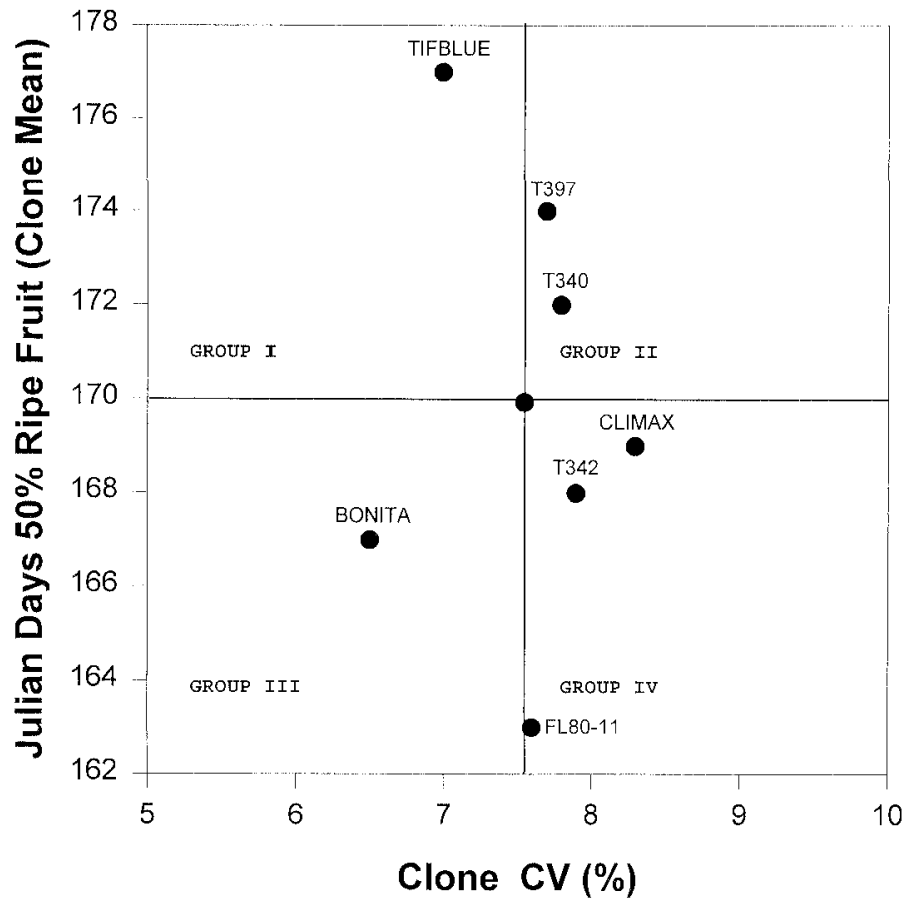




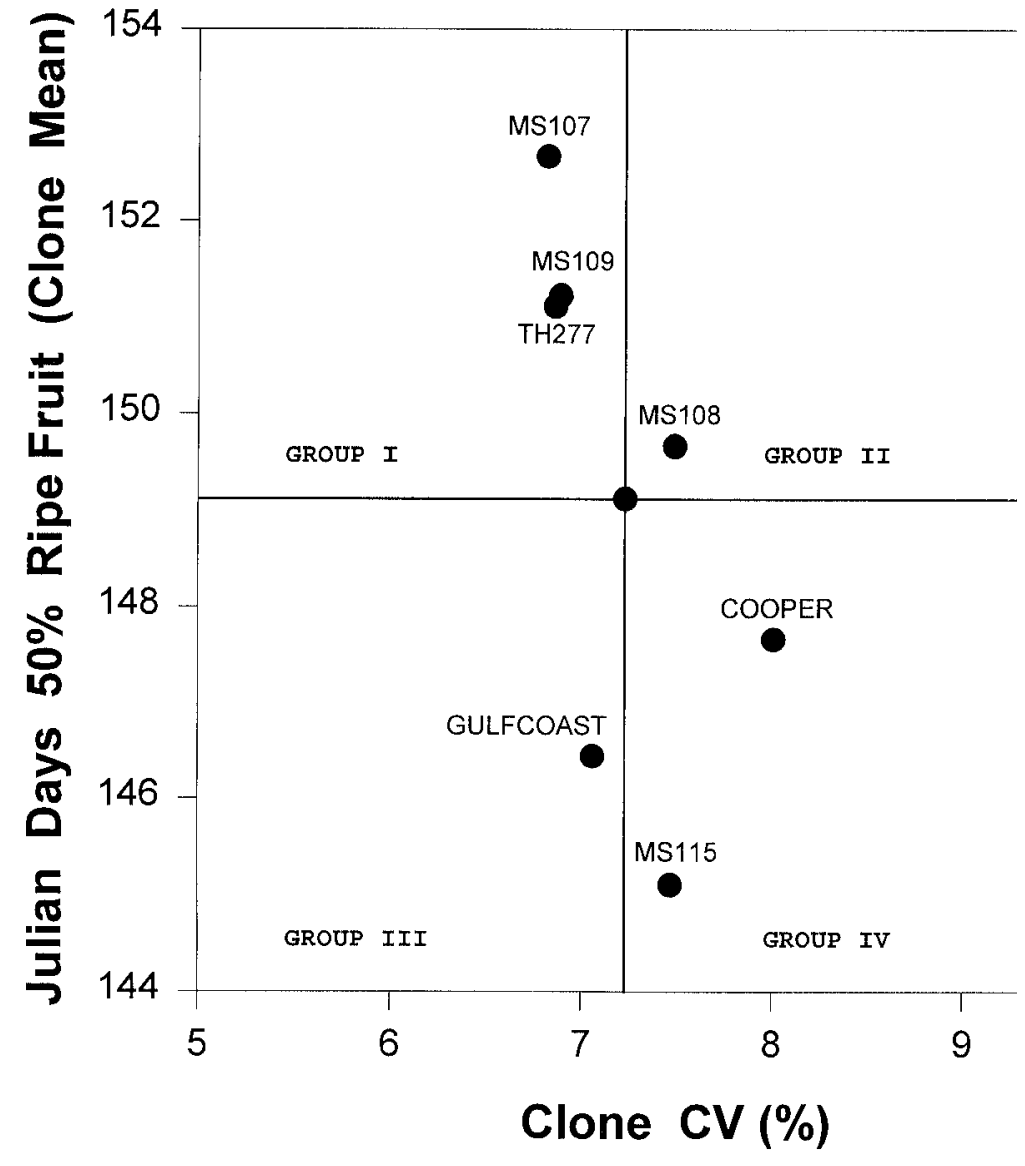

\section{Results}

Analyses of variance of the entire data set indicated that clone, environment, and clone $x$ environment interactions were significant $(P$ $<0.0005)$. This suggested that stability analyses were warranted.

Type 1 and Type 2 stability statistics. For Type 1 stability, 'Bonita' was the most stable rabbiteye clone with respect to ripening date and yield; 'Climax' was the least stable for ripening date and 'Tifblue' was the least stable for yield (Table 1). For Type 2 stability, 'Bonita' was also the most and 'Climax' the least stable for ripening date. FL80-11 and T342 were most stable while 'Tifblue', 'Climax', and T340 were the least stable for yield.

Type 1 stability for ripening date of southern highbush types were highest for TH277, 'Gulfcoast', and MS107, and lowest for 'Cooper' (Table 1). MS107 and MS115 were most stable and 'Gulfcoast' was least stable for yield. 'Gulfcoast' was most stable and TH277 least stable for Type 2 ripening date. MS107 was the most consistent and MS115 the least consistent over environments for yield.

Fig. 3. Clone yield means versus clone CV from seven rabbiteye clones grown in nine environments.
Fig. 2. Clone ripening date means versus clone $\mathrm{CV}$ from seven southern highbush clones grown in nine environments.

were defined as those in which the associated genotype had an environmental index greater than zero. Two regression lines were computed for each genotype, one for the poor and one for the good environment. An analysis of covariance was conducted to statistically compare the regression lines of poor versus good environments. The effects tested were slope, means, and slope of the combined poor and good environments.

Cluster analyses. The dissimilarity index proposed by Lin et al. (1986) was calculated for ripening date and yield responses. These indices were used to conduct cluster analyses by the average linkage method of Sokal and Michener (1958) available in the cluster procedure of SAS (Cary, N.C.). Cluster solutions containing two, three, four, and five clusters were obtained for each response. The cluster solution best representative of the actual similarity pattern among RE and SHB clones was determined statistically. Either a small root mean square standard deviation or a small normalized root mean square distance for a small number of clusters together with a large $R^{2}$ identified the best solution.

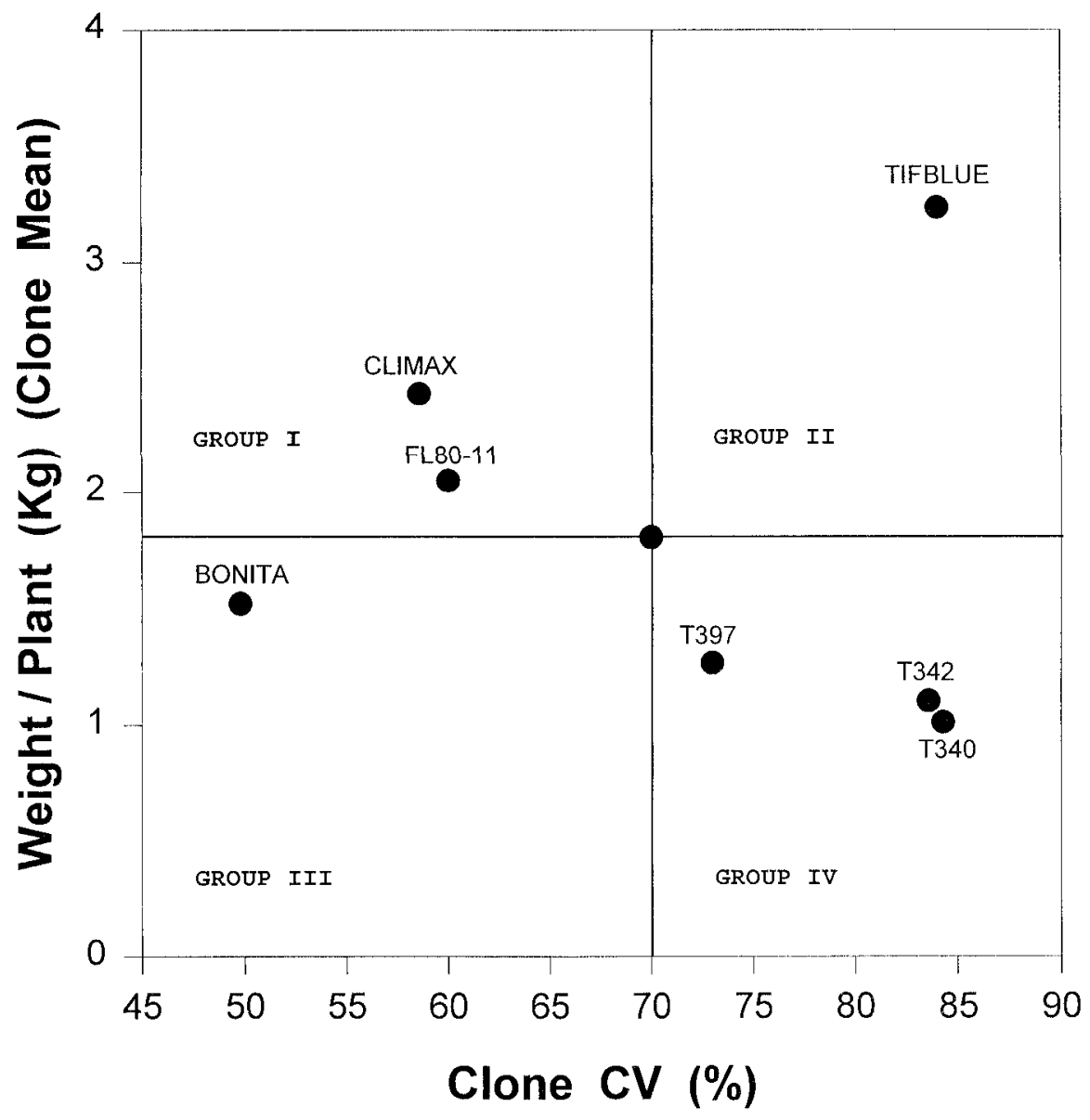

J. Amer. Soc. Hort. ScI. 121(2):204-209. 1996. 

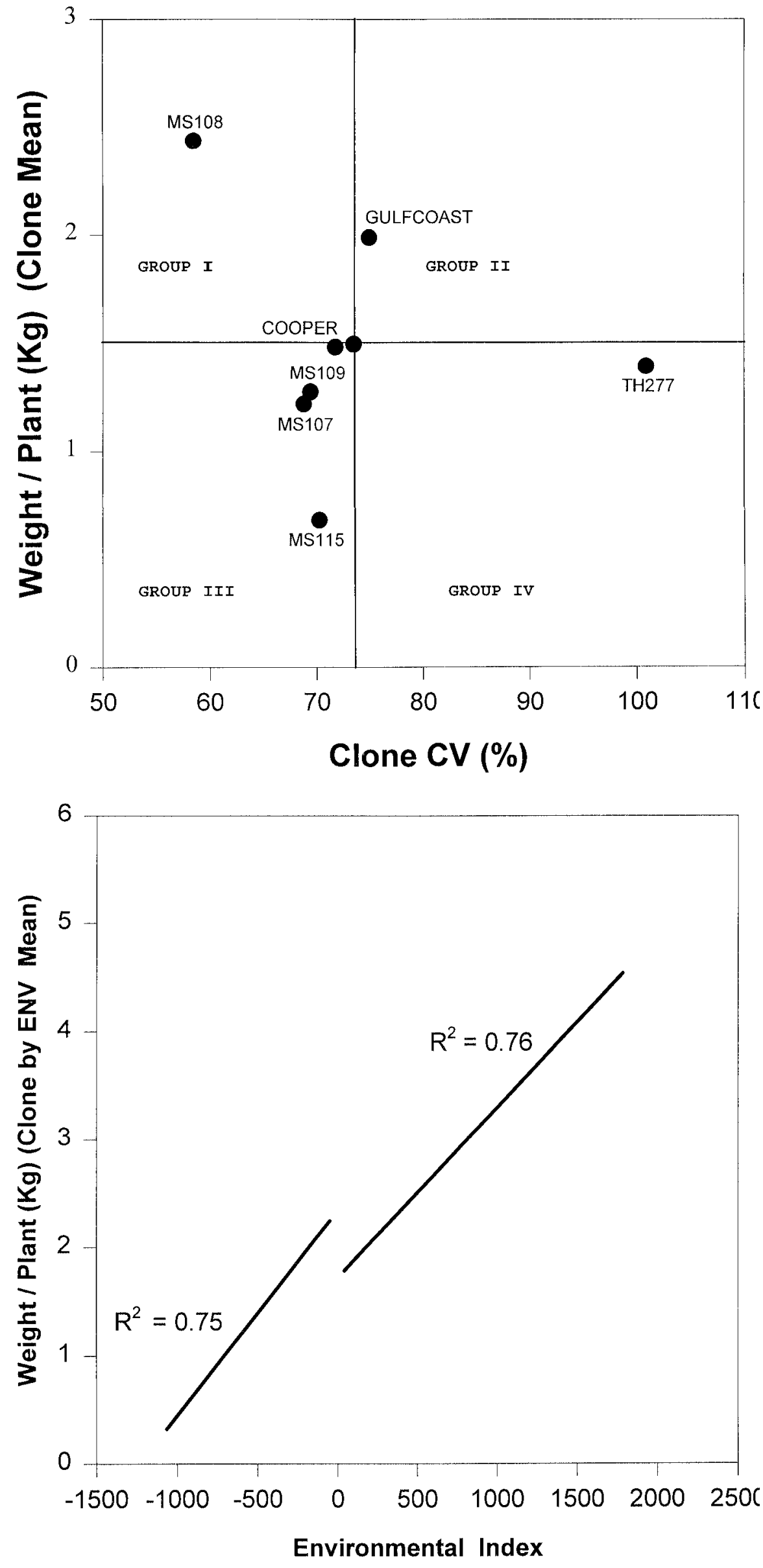

Fig. 4. Clone yield means versus clone $\mathrm{CV}$ from seven southern highbush clones grown in nine environments.

Francis and Kannenberg grouping. An early ripening date in the southern United States is desirable in blueberry, therefore, Group III is the preferred stability level of the rabbiteye clones. Only 'Bonita' appears in this group (Fig. 1). FL80-11, T342, and 'Climax' ripened early but were more variable among environments than 'Bonita'. 'Tifblue' was stable but late ripening. Of the southern highbush clones, only 'Gulfcoast' was early ripening and stable (Fig. 2).

Group I clones are the most desirable for yield; rabbiteye clones 'Climax' and FL80-11 appeared in this group (Fig. 3). 'Tifblue' was the highest yielding genotype but was also among the most variable clones among environments. MS108 was the most stable southern highbush clone. 'Gulfcoast' produced a high yield but was more variable among environments than MS108 (Fig. 4).

Environmental index regression. No ideal response (stable in poor environments and positive response to good environments) for either early ripening or yield was found, e.g., the response of 'Gulfcoast' (Fig. 5). Either the slopes and means for good and poor environments did not differ significantly or $R^{2}$ was not significant, therefore, no curvilinear relationship was found. Rabbiteye clones 'Bonita', 'Climax', FL80-11, T340, T342, and southern highbush clones 'Gulfcoast', MS108, and MS109 produced later ripening fruit with progressively better environments. Yields of 'Cooper', 'Gulfcoast', MS107, MS109, and TH277 also responded positively to good environments. None of the rabbiteye genotypes were stable for yield by the two-regression index.

Cluster analysis. The three cluster solution was statistically preferable for ripening date and yield of RE and SHB clones. Cluster 1 and 2 RE clone ripening dates (Table 2) are not distinguishable subjectively. Cluster 3 , 'Tifblue', is the latest ripening RE clone, and corresponded to clones whose slopes in the regression analyses were negative in the poor but positive in the good environments, means were equal in the two environments, and the overall slope was zero. SHB Cluster 2 clones were earliest ripening and ranked similarly for ripening date across environments. SHB cluster 1 clones had similar patterns of rank over environments and were intermediate in ripening date. Cluster 3 comprised the latest ripening SHB clones.

Fig. 5. Regression of 'Gulfcoast' yield on poor environments ( -1000 to 0$)$ and good environments (0 to 2000). 
Table 2. Three clusters from the cluster analyses of seven rabbiteye and seven southern highbush clones across nine environments for ripening date and yield.

\begin{tabular}{|c|c|c|c|c|c|}
\hline \multicolumn{6}{|c|}{ Julian date at which half of RE fruit was ripe } \\
\hline \multicolumn{2}{|c|}{ Cluster 1} & \multicolumn{2}{|c|}{ Cluster 2} & \multicolumn{2}{|c|}{ Cluster 3} \\
\hline Clone & Julian date & Clone & Julian date & Clone & Julian date \\
\hline Bonita & 167 & Climax & 169 & Tifblue & 177 \\
\hline \multirow[t]{4}{*}{ T397 } & 174 & FL80-11 & 163 & & \\
\hline & & T340 & 172 & & \\
\hline & & $\mathrm{T} 342$ & 168 & & \\
\hline & & \multicolumn{2}{|c|}{ Yield of RE clones } & & \\
\hline \multicolumn{2}{|c|}{ Cluster 1} & \multicolumn{2}{|c|}{ Cluster 2} & \multicolumn{2}{|c|}{ Cluster 3} \\
\hline Clone & Yield (g/plant) & Clone & Yield (g/plant) & Clone & Yield (g/plant) \\
\hline$\overline{\text { Bonita }}$ & 1522 & Climax & 2433 & Tifblue & 3233 \\
\hline $\mathrm{T} 340$ & 1016 & FL80-11 & 2052 & & \\
\hline T397 & 1269 & $\mathrm{~T} 342$ & 1108 & & \\
\hline \multicolumn{6}{|c|}{ Julian date at which half of SHB fruit was ripe } \\
\hline \multicolumn{2}{|c|}{ Cluster 1} & \multicolumn{2}{|c|}{ Cluster 2} & \multicolumn{2}{|c|}{ Cluster 3} \\
\hline Clone & Julian date & Clone & Julian date & Clone & Julian date \\
\hline Cooper & 148 & Gulfcoast & 146 & MS107 & 153 \\
\hline \multirow[t]{3}{*}{ MS109 } & 151 & MS115 & 145 & MS108 & 150 \\
\hline & & & & TH277 & 151 \\
\hline & & Yield & B clones & & \\
\hline \multicolumn{2}{|c|}{ Cluster 1} & \multicolumn{2}{|c|}{ Cluster 2} & \multicolumn{2}{|c|}{ Cluster 3} \\
\hline Clone & $\overline{\text { Yield (g/plant) }}$ & Clone & $\overline{\text { Yield (g/plant) }}$ & Clone & Yield (g/plant) \\
\hline Cooper & 1486 & MS108 & 2441 & MS115 & 682 \\
\hline Gulfcoast & 1991 & & & & \\
\hline MS107 & 1222 & & & & \\
\hline MS109 & 1277 & & & & \\
\hline TH277 & 1396 & & & & \\
\hline
\end{tabular}

RE clones in cluster 2 (Table 2) produced low yields that were variable among environments. None of the cluster 1 clones responded to good environments in the regression analysis. Yields of clones in Cluster 2 were intermediate and generally variable among environments. Those clones did not respond to good environments in the regression analysis. Cluster 3, 'Tifblue', produced the highest average yield but did not rank first in all environments. Clones in SHB Cluster 1 produced intermediate yields that were variable among environments. SHB Cluster 2, MS108, ranked either first or second in yield in each environment and produced the highest average yield of the SHB clones. Cluster 3 , MS115, produced consistently low yields across environments.

\section{Discussion}

The concept of stability has been parametrized in numerous ways and interpretations of stability statistics are ambiguous. Empirical comparisons among methods utilized in this study were designed to determine which, if any, might best identify wellbuffered blueberry genotypes for the southern United States.

'Tifblue' is the most widely grown rabbiteye cultivar in existence (Spiers, 1990) and was the highest yielding clone in the regional trials, but it was judged the least stable for yield by Type 1 and Type 2 statistics. MS108 was the highest and 'Gulfcoast' was the second highest yielding SHB clone in the regional trials. MS108 yielded high and should be judged stable because it escaped frost damage in some environments; yet, MS108 and 'Gulfcoast' were not stable by Type 1 and Type 2 statistics. The most stable genotypes in both blueberry types were those that were among the lowest yielding in the trials. These results agree with previous reports that Type 1 stability is often associated with a relatively poor response and low yield in environments that produce high yields in other genotypes (Lin et al., 1986). Type 2 stability depends upon the genotypes included in the test so that a clone that appears stable in one test may not be judged stable in another set of genotypes. The usefulness of Type 2 stability may be restricted in a germplasm evaluation program because the entries usually are not representative of those grown in the area.

Francis and Kannenberg (1978) recommended simple plots that illustrate the response mean and variation of each genotype across the environments observed. This method is an improvement over Type 1 stability estimates because both the mean and variance of the individual clones are considered. Clones with a low CV must also be high yielding to be deemed stable. Mean performance of a clone can be quickly determined visually from the plots. Clone cvs were generally low for ripening date but high for yield as is typical for blueberries. The highest yielding rabbiteye and southern highbush clones were also among the most variable.

Verma et al. (1978) stated that a theoretically ideal genotype would be one that possesses a relatively high yield and stable performance in low-yielding environments and the capacity to respond to favorable environments. Furthermore, biological relationships often are not linear and assuming a linear response of genotypes to an environmental gradient may lead to erroneous conclusions. Using their approach to create an environmental index with a mean of zero and performing separate regression analyses for negative and positive environmental indices did not suggest curvilinear relationships in either ripening date or yield of 
blueberry. This needs to be confirmed or rejected by further evaluation of different genotypes in different environments. In the absence of curvilinear relationships, linear regressions using all indices would be preferable because of the larger degrees of freedom in the analysis.

Cluster analyses account for a genotypes' multivariate response to environments by grouping genotypes according to their response structure. Lin et al. (1986) stated that by including a wellknown cultivar in the test, all genotypes in the same cluster may be regarded as having the overall characteristics of this cultivar, making it possible to extrapolate the genotypes to a much wider range of environments than those tested. 'Tifblue' appeared alone in clusters for ripening date and yield, suggesting that no clone in the test was similar to it.

Members of each cluster form distinct groups when they are circled on the Francis and Kannenberg graphs; however, classification of the clusters differ from those of the graphs. In some instances cluster composition is obvious and in others it is not. 'Tifblue' stands alone as the latest ripening RE clone with a low CV and highest yielding RE clone with a high CV. MS108 stands alone as the highest yielding SHB clone with the lowest CV. The ability of MS108 flowers to escape early spring freezes undoubtedly contributed to its low CV. It was not released as a cultivar because of a poor picking scar and flavor.

Disadvantages of using Type 1 and Type 2 stability statistics (Lin et al., 1986), coefficients of variability (Pritts and Luby, 1990), regression (Verma et al., 1978), and deviations from regression (Lin et al., 1986) render it difficult to assess stability. Inferences on stability from the methods compared in this study conflicted as in previously reported results (Lin et al., 1986, Pritts and Luby, 1990). The two-regression model of Verma et al. (1978) was not useful in this study because no curvilinear relationship was shown.

The nonparametric approach with known cultivars included appears to be most useful compared to other methods of estimating stability studied. Under circumstances of conflicting inferences from parametric approaches, a better procedure is to describe the genotypes qualitatively, i.e., adopt a nonparametric clustering procedure (Lin et al., 1986). The advantage of clustering is that although genotypes are grouped based on a specific data set, the relative relationship among genotypes can be independent of the specific set of data analyzed. For example, a cluster analysis of one set may give the groups (B) (ACDE) and another set (A) (BFGH). In either case, $A$ and $B$ are in different groups and are dissimilar.

Agronomic stability appears to be more associated with resiliency i.e. the capacity to adjust to different environments than with low variability. MS 108 was the least variable SHB clone and produced the highest yields across environments, however, 'Tifblue' was the most variable RE clone but also produced the highest yields. These results agree with those of Siefker and Hancock (1986) that the highest yielding highbush cultivars were the most stable. Pritts and Luby (1990) stated that, for many quantitative traits, it may not be desirable for a genotype to have low variability because a desirable cultivar should respond positively to improved environmental conditions rather than exhibit a constant performance.

\section{Literature Cited}

Francis, T.R. and L.W. Kannenberg. 1978. Yield stability studies in shortseason maize. I. A descriptive method for grouping genotypes. Can. J. Plant Sci. 58:1029-1034.

Gupton, C., M. Austin, M. Burns, J. Caldwell, J. Clark, P. Lyrene, D. Makus, C. Mullins, and J. Spiers. 1990. Performance of blueberry germplasm in diverse environments. Proc. 6th North American Blueberry Research Extension Workers Conf., 10-12 July 1990, Portland, Ore. p. 28-35.

Lin, C.S., M.R. Binns, and L.P. Lefkovitch. 1986. Stability analysis: Where do we stand? Crop Sci. 26:894-900.

Nassar, R. and M. Huhn. 1987. Studies on estimation of phenotypic stability: Test of significance for nonparametric measures of phenotypic stability. Biometrics 43:45-53.

Pritts, M. and J. Luby. 1990. Stability indices for horticultural crops. HortScience 25:740-745.

Siefker, J.H. and J.F. Hancock. 1986. Stability of yield in highbush blueberry cultivars. Fruit Var. J. 40:5-7.

Sokal, R.R. and C.D. Michener. 1958. A statistical method for evaluating systematic relationships. Univ. of Kansas Sci. Bul. 38. p. 1409-1438.

Spiers, J.M. 1990. Rabbiteye blueberry. Fruit Var. J. 44:68-72.

Verma, M.M., C.S. Chahal, and B.R. Murty. 1978. Limitations of conventional regression analysis: A proposed modification. Theor. Appl. Genet. 53:89-91.

Yates, F. and W.G. Cochran. 1938. The analysis of groups of experiments. J. Agr. Sci. 28:556-580. 